\title{
Progress towards tuberculosis elimination: secular trend, immigration and transmission
}

\author{
M.W. Borgdorff*,\#, S. van den Hof ${ }^{\#,}$, K. Kremer ${ }^{+}$, L. Verhagen ${ }^{+}$, N. Kalisvaart ${ }^{\ddagger}$, \\ C. Erkens ${ }^{4}$ and D. van Soolingen ${ }^{+}$
}

ABSTRACT: This study aimed to determine to what extent tuberculosis trends in the Netherlands depend on secular trend, immigration and recent transmission.

Data on patients in the Netherlands Tuberculosis Register in the period 1993-2007 were matched with restriction fragment length polymorphism (RFLP) patterns of Mycobacterium tuberculosis isolates. Index patients were defined as patients with pulmonary tuberculosis whose isolates had RFLP patterns not observed in another patient in the previous $2 \mathrm{yrs}$.

Among 8,330 patients with pulmonary tuberculosis the isolates of $56 \%$ of native and $50 \%$ of foreign-born patients were clustered. Of these, 5,185 were included in detailed analysis: 1,376 native index patients, 2,822 foreign-born index patients and 987 secondary cases within 2 yrs of diagnosis of the index case. The incidence of native and foreign-born index patients declined by $6 \%$ and $2 \%$ per year, respectively. The number of secondary cases per index case was 0.24 . The decline of native cases contributed most to the overall decline of tuberculosis rates and was largely explained by a declining prevalence of latent infection. Tuberculosis among immigrants was associated with immigration figures.

Progress towards elimination of tuberculosis would benefit from intensifying diagnosis and treatment of latent infection among immigrants and global tuberculosis control.

KEYWORDS: Infectious diseases epidemiology, molecular epidemiology, prevention and control, tuberculosis

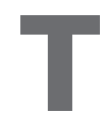
uberculosis (TB) is caused by Mycobacterium tuberculosis and may result from rapid disease progression, defined as progression to disease within $1-5 \mathrm{yrs}$ after (re-)infection, or from endogenous reactivation of latent infection up to decades after infection [1-3]. Moreover, in particular among the foreignborn [4], cases occur after recent or remote infection outside the study area.

Genotyping of M. tuberculosis isolates using restriction fragment length polymorphism (RFLP) with IS6110 and the polymorphic GC rich sequence (PGRS) as markers in principle allows a separation of disease attributable to recent transmission and disease attributable to reactivation or importation [5]. The RFLP patterns of $M$. tuberculosis isolates of patients with disease due to recent transmission are likely to have been observed in at least one other patient in recent years, provided that infection took place within the study area, that the vast majority of patients were captured and that their isolates were subjected to genotyping [6]. If such a DNA fingerprint was not observed, disease was probably due to reactivation or importation.

Using molecular epidemiological methods, declining TB rates in New York, NY, USA [4], San Francisco, CA, USA [7] and Madrid, Spain [8] in the 1990s were attributed to improved control which led to lower TB rates attributable to recent transmission. Declining TB rates in the Netherlands [9] and in Arkansas, USA [10] around the beginning of this millennium were attributed to declining TB rates attributable to endogenous reactivation of latent infection, which in the Netherlands was attributed to a cohort effect [9].

In the Netherlands, annual TB case numbers declined from $>1,500$ in 1993 to $<1,000$ in 2007 (fig. 1). The present study aimed to extend previous analyses [9] by covering a longer time period, exploring quantitative support for a cohort effect among natives, and assessing the association of $\mathrm{TB}$

Earn CME accreditation by answering questions about this article. You will find these at the back of the printed copy of this issue or online at www.erj.ersjournals.com/misc/cmeinfo.dtl 
among the foreign-born with immigration figures. Specifically, we determined to what extent the decline of TB incidence in the period 1995-2007 was explained by the following three factors: 1) reduced TB rates attributable to endogenous reactivation in the native population; 2) reduced importation; and 3) reduced TB rates attributable to rapid progression after transmission within the Netherlands.

\section{METHODS}

TB is a notifiable disease in the Netherlands. Since 1993, information on risk factors and treatment outcome has been entered in the Netherlands Tuberculosis Register (NTR) maintained by the KNCV Tuberculosis Foundation. Crossmatching with notification data suggested over $99 \%$ completeness up to 2003. Since 2004, notification and voluntary registration take place with a single internet-based system and discrepancies have been reduced to zero. For this study we used data on age, sex, year of diagnosis, pulmonary localisation of TB, direct sputum smear result for acid-fast bacilli, country of birth, urban residence and risk group. We refer to those born in the Netherlands as the native population.

All M. tuberculosis complex isolates of patients diagnosed in the Netherlands are subjected to species identification, DNA fingerprinting and drug susceptibility testing. In the period 1993-2007 DNA fingerprinting was performed with standard

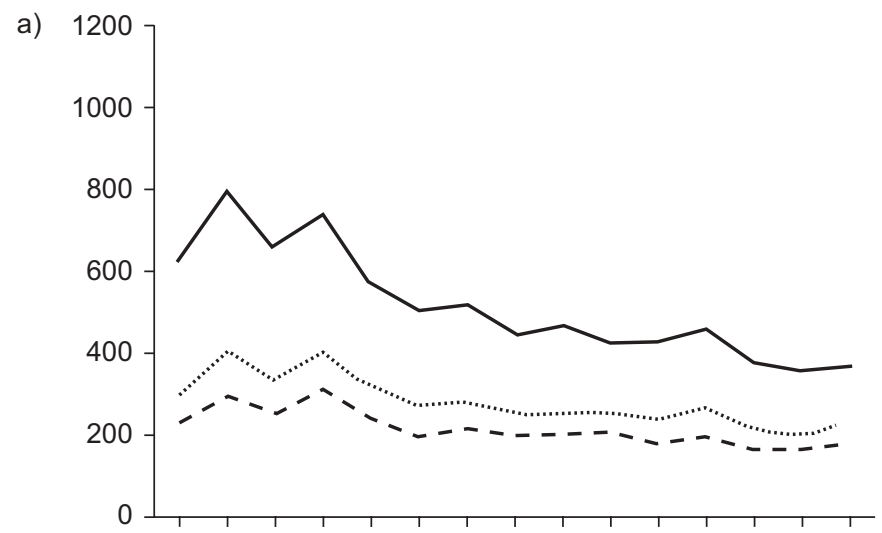

b)

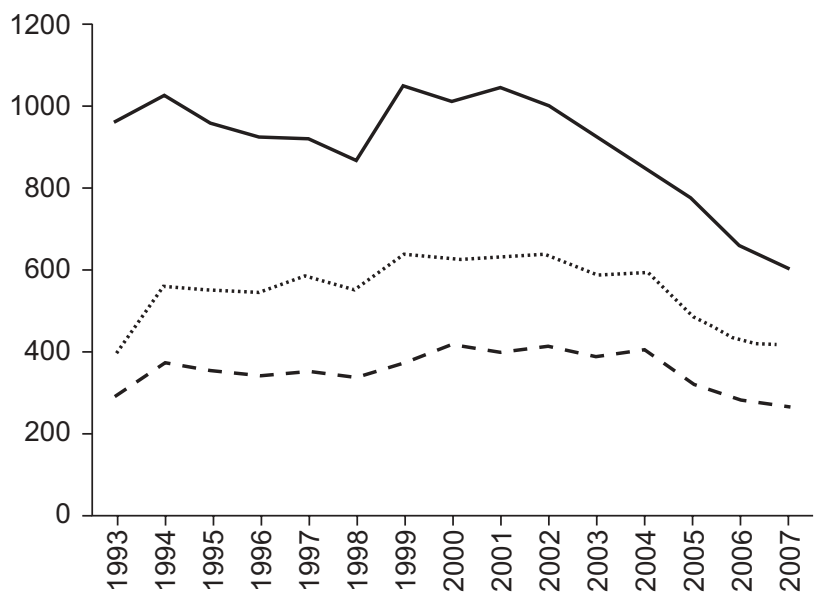

FIGURE 1. Trends of tuberculosis (all cases, - $\longrightarrow$ ), tuberculosis with genotyping results $(\cdots \cdots \cdot)$, and pulmonary tuberculosis with genotyping results (----) among a) native and b) foreign-born patients in the Netherlands, 1993-2007.
RFLP typing using IS6110 as a probe [11]. Strains with fewer than five IS6110 copies in RFLP typing were subjected to subtyping with the PGRS probe [12]. Information in the two databases was matched using sex, date of birth, postal area code and year of diagnosis as identifiers.

In the period 1993-2007, 21,155 patients were diagnosed with $\mathrm{TB}$, with 14,818 (70\%) confirmed by culture. Matching patient data to DNA fingerprinting results yielded a total of 12,222 $(82 \%)$ culture-confirmed patients with information on the genotype of their M. tuberculosis isolate. Since TB is transmitted by patients with culture-positive pulmonary $\mathrm{TB}$, the analysis of clustering was restricted to 8,330 patients with pulmonary TB. Clusters were defined as groups of two or more patients who had isolates with identical DNA fingerprints at any time in the period 1993-2007. For each calendar year we determined the population strain diversity of $M$. tuberculosis as the number of different RFLP patterns divided by the total number of isolates [13].

Previously, we defined the transmission index as the number of secondary cases per potential source case using clustering over the complete study period $[14,15]$. As the study duration gets longer, this approach is unsatisfactory, since the duration of follow-up is shorter for potential source cases occurring late in the study period than for those occurring early. Moreover, the attribution of secondary cases to the potential source case becomes increasingly inaccurate with time, because of propagated transmission by second and further generation source cases within the cluster.

In order to choose a cut-off point for the definition of recent transmission we determined the probability that an isolate would be followed by one with an identical genotype with Kaplan-Meier survival analysis [7, 9]. The Kaplan-Meier probability of finding another case with identical fingerprint within 5 yrs was 0.40 and within 2 yrs was 0.33 , i.e., $83 \%$ of the 5 -yr probability. Therefore, we defined index cases as patients with strains not seen in other patients in the previous 2 yrs [9]. Most of these index patients are likely to have had reactivation or imported disease [16]. The transmission index was defined as the number of secondary cases within 2 yrs per index case. In a sensitivity analysis, we explored the consequences of using a 1- or 3-yr period to define recent transmission.

The trend of the incidence of native index cases was used as an indicator of secular trend, while among the foreign-born we determined the association with recent immigration figures. The number of secondary cases was used as an indicator of TB attributable to recent transmission. In this analysis we excluded index cases in 1993 and 1994 and their secondary cases (in total 1,867), since we were unable to determine whether strains of these index cases had not been observed in the previous 2 yrs. We excluded 687 index cases and their secondary cases in 2006-2007, since we were unable to follow these index cases for a full 2-yr period. Finally, we excluded 591 cases occurring $<2$ yrs after a previous patient with that fingerprint, but $>2$ yrs after the start of a cluster in 1995-2005. Thus, 5,185 patients remained: 3,624 non-clustered index patients, 574 index patients who were the first patient of a cluster and 987 secondary cases within 2 yrs of the start of the cluster. Because in the sensitivity analysis we included the 
effect of a 3-yr period to define recent transmission, we restricted this to index patients in the period 1996-2004 and their secondary cases.

Population denominators and immigration figures were obtained from the Central Bureau of Statistics [17]. Countries were classified by total TB incidence $(<50,50-199$ and $\geqslant 200$ per 100,000) estimated by the World Health Organization [18].

Person-years were estimated by the mid-year population. We determined the incidence of index cases and identified associated risk factors with Poisson regression for the native and foreign-born population [19]. We estimated to what extent the reduced incidence of native index cases may be attributed to a cohort effect by relating the decline in index cases to the estimated decline in numbers of people with latent TB infection (LTBI). The age-specific proportion of people with LTBI was estimated by STYBLO [20], assuming that the risk of infection is independent of age and sex, and that the risk of infection since 1988 would have a negligible effect on the agespecific prevalence of infection. The expected number of native index cases in 2005 was estimated, given the number of native index cases by age in 1995 and the decline in the number of people with LTBI. The expected number of index cases was then compared with the observed number. We used Poisson regression, with an offset of one for each index case, to identify characteristics of index cases associated with the number of secondary cases [19].

\section{RESULTS}

\section{Clustering}

Of the isolates, $56 \%(1,756$ out of 3,116$)$ were clustered among native patients and $50 \%(2,594$ out of 5,214$)$ among foreignborn patients (table 1). Among natives, the incidence of nonclustered pulmonary TB declined by $4.9 \%$ per year $(95 \% \mathrm{CI}$

TABLE 1 Incidence of clustered and non-clustered pulmonary tuberculosis in the native and foreign-born population in the Netherlands, 1993-2007

\begin{tabular}{|c|c|c|c|c|c|c|}
\hline \multirow[t]{2}{*}{ Year } & \multirow[t]{2}{*}{ Clustered $\mathbf{n}$} & \multirow[t]{2}{*}{ Non-clustered $\mathbf{n}$} & \multirow[t]{2}{*}{ Person-yrs $\times 100000$} & \multicolumn{2}{|c|}{ Rates per 100000} & \multirow[t]{2}{*}{ Per cent clustereo } \\
\hline & & & & Clustered & Non-clustered & \\
\hline \multicolumn{7}{|l|}{ Native } \\
\hline 1993 & 127 & 97 & 141 & 0.9 & 0.7 & 57 \\
\hline 1994 & 163 & 130 & 141 & 1.2 & 0.9 & 56 \\
\hline 1995 & 116 & 129 & 142 & 0.8 & 0.9 & 47 \\
\hline 1996 & 178 & 125 & 142 & 1.3 & 0.9 & 59 \\
\hline 1997 & 111 & 120 & 143 & 0.8 & 0.8 & 48 \\
\hline 1998 & 102 & 87 & 143 & 0.7 & 0.6 & 54 \\
\hline 1999 & 132 & 76 & 144 & 0.9 & 0.5 & 63 \\
\hline 2000 & 115 & 80 & 145 & 0.8 & 0.6 & 59 \\
\hline 2001 & 119 & 74 & 145 & 0.8 & 0.5 & 62 \\
\hline 2002 & 120 & 72 & 146 & 0.8 & 0.5 & 63 \\
\hline 2003 & 88 & 84 & 146 & 0.6 & 0.6 & 51 \\
\hline 2004 & 110 & 79 & 147 & 0.7 & 0.5 & 58 \\
\hline 2005 & 98 & 59 & 147 & 0.7 & 0.4 & 62 \\
\hline 2006 & 83 & 71 & 147 & 0.6 & 0.5 & 54 \\
\hline 2007 & 94 & 77 & 148 & 0.6 & 0.5 & 55 \\
\hline Total & 1756 & 1360 & 3116 & 0.8 & 0.6 & 56 \\
\hline \multicolumn{7}{|c|}{ Foreign born } \\
\hline 1993 & 142 & 144 & 12 & 11.7 & 11.8 & 50 \\
\hline 1994 & 193 & 171 & 13 & 15.4 & 13.7 & 53 \\
\hline 1995 & 171 & 177 & 13 & 13.4 & 13.9 & 49 \\
\hline 1996 & 167 & 165 & 13 & 12.9 & 12.7 & 50 \\
\hline 1997 & 176 & 167 & 13 & 13.3 & 12.6 & 51 \\
\hline 1998 & 166 & 169 & 14 & 12.1 & 12.4 & 50 \\
\hline 1999 & 197 & 171 & 14 & 14.0 & 12.1 & 54 \\
\hline 2000 & 205 & 204 & 15 & 14.0 & 14.0 & 50 \\
\hline 2001 & 191 & 203 & 15 & 12.6 & 13.4 & 48 \\
\hline 2002 & 203 & 204 & 16 & 13.0 & 13.0 & 50 \\
\hline 2003 & 205 & 179 & 16 & 12.9 & 11.2 & 53 \\
\hline 2004 & 195 & 202 & 16 & 12.2 & 12.6 & 49 \\
\hline 2005 & 143 & 171 & 16 & 8.9 & 10.7 & 46 \\
\hline 2006 & 127 & 147 & 16 & 7.9 & 9.2 & 46 \\
\hline 2007 & 113 & 146 & 16 & 7.1 & 9.1 & 44 \\
\hline Total & 2594 & 2620 & 5214 & 12.0 & 12.1 & 50 \\
\hline
\end{tabular}


$3.7-6.1 \%$ ) and that of clustered TB by $3.7 \%$ (95\% CI $2.7-4.8 \%$ ). Among the foreign-born, the incidence of non-clustered TB declined by $1.9 \%$ per year $(95 \%$ CI $1.0-2.7 \%)$ and that of clustered TB by $3.1 \%$ (95\% CI 2.2-4.0\%). Population strain diversity in each year was, on average, 0.81 and did not change over time (slope $0.0004,95 \%$ CI $-0.002-0.003$ ). We observed 4,936 strains among 8,330 patients. The probability that two randomly selected patients had the same strain was 0.0008 .

\section{Trends in incidence of native index cases}

The incidence of native index cases was on average 0.9 per 100,000 . The incidence was 1.7 times higher among males than females, and increased steeply with age (table 2). The annual decline was $6 \%$ overall, and depended on the age of the index patient: in the age group $\geqslant 75$ yrs it was $8 \%(95 \%$ CI $5-10 \%)$, in age group $65-74$ yrs $11 \%$ (95\% CI 7-15\%), 45-64 yrs 3\% (95\% CI $0-7 \%$ ) and $<45$ yrs $5 \%(95 \%$ CI $2-8 \%)$.
From 1995 to 2005 the estimated size of the native population with LTBI declined from 1.70 to 0.98 million (table 3 ). The expected and observed numbers of index cases in 2005 were 91 and 91 , respectively (standardised ratio $1.00,95 \%$ CI $0.81-1.23$ ). The observed number of cases was higher than expected in those aged $<65$ yrs (standardised ratio $1.79,95 \%$ CI 1.33-2.35) and lower than expected in those aged $\geqslant 65 \mathrm{yrs}$ and more (standardised ratio 0.65, 95\% CI 0.47-0.88).

\section{Trends in incidence of foreign-born index cases}

Among the foreign-born, the incidence of index cases was 17.6 per 100,000 . The crude incidence ratio of foreign-born versus those born in the Netherlands was 20.4 (95\% CI 19.1-21.7). The incidence was 1.7 times higher among males than females, and was highest in the age group 15-34 yrs (table 2). Among the foreign-born, the incidence of index cases declined by $2 \%$ per year, irrespective of age. The number of immigrants in the

TABLE 2 Incidence of tuberculosis (TB) index cases in the native and foreign-born population in the Netherlands, 1995-2005

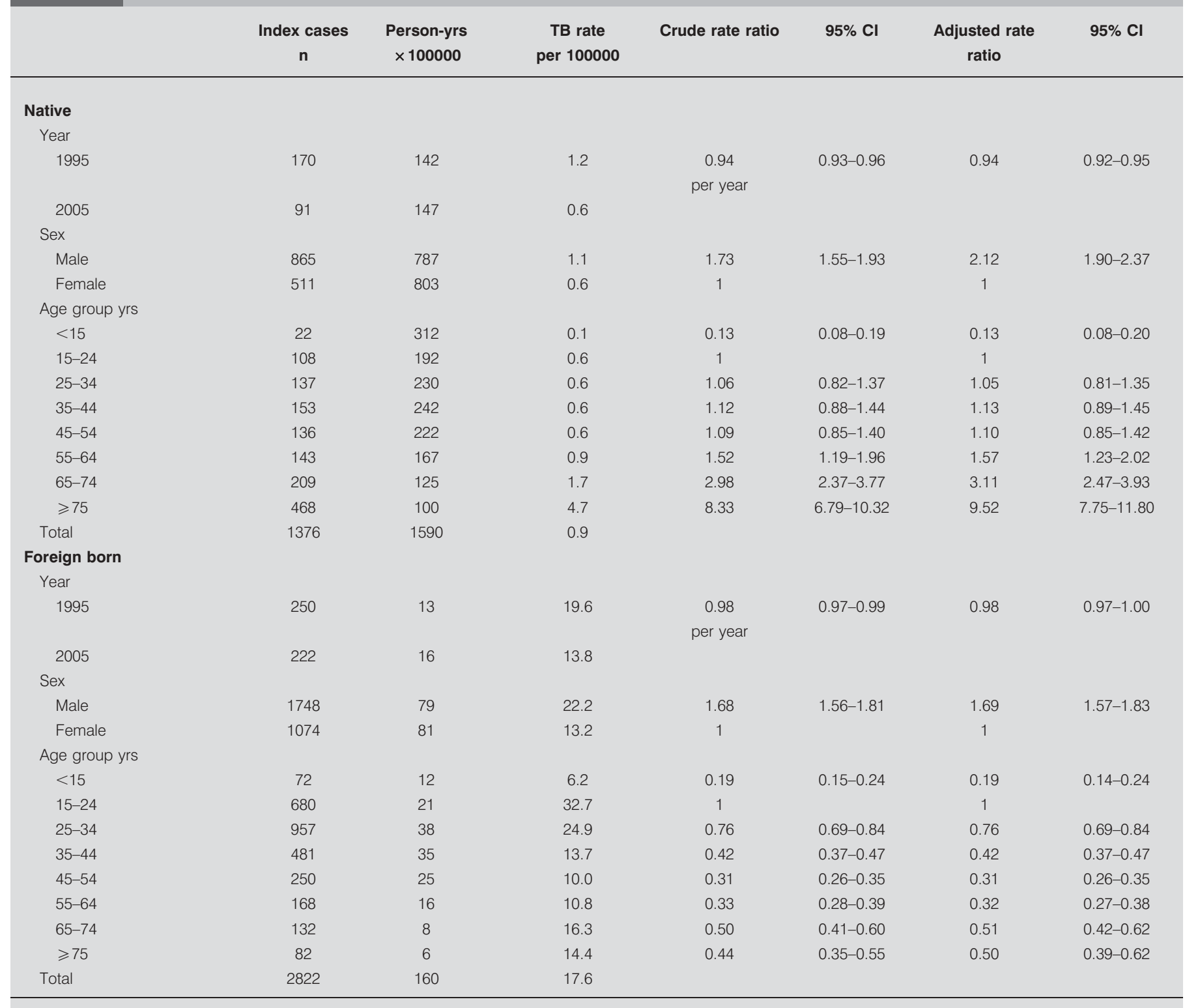




\begin{tabular}{|c|c|c|c|c|c|}
\hline TABLE 3 & $\begin{array}{l}\text { evalence of latent tuberci } \\
\text { etherlands in } 1995 \text { and } 20\end{array}$ & sis infectic & and incic & of index cases in the $n$ & population in the \\
\hline \multirow[t]{2}{*}{ Age yrs } & \multirow[t]{2}{*}{ Index cases observed 1995} & \multicolumn{2}{|c|}{ Population with LTBI $\times 100000$} & \multirow[t]{2}{*}{ Index cases expected $2005^{\#}$} & \multirow[t]{2}{*}{ Index cases observed 2005} \\
\hline & & 1995 & 2005 & & \\
\hline$<15$ & 2 & 0.01 & 0.00 & 0.5 & 2 \\
\hline $35-44$ & 17 & 0.53 & 0.20 & 6.3 & 8 \\
\hline $45-54$ & 19 & 1.44 & 0.52 & 6.8 & 16 \\
\hline $55-64$ & 14 & 3.27 & 1.36 & 5.8 & 9 \\
\hline $65-74$ & 33 & 5.45 & 2.84 & 17.2 & 8 \\
\hline$\geqslant 75$ & 58 & 6.08 & 4.83 & 46.1 & 33 \\
\hline
\end{tabular}

Data are presented as $\mathrm{n}$, unless otherwise stated. The age specific proportion with LTBI was obtained from BRESLow et al. [19], the population denominator from the Central Bureau of Statistics [17]. * : calculated as (index cases observed in 1995) $\times$ (population with LTBI in 2005)/(population with LTBI in 1995).

period 1995-2005 from countries with estimated incidences of $<50,50-199$, and $\geqslant 200$ per 100,000 was $318,000,284,000$ and 120,000 , respectively. The number of index cases among the foreign-born was significantly associated with the number of immigrants in the same year from countries with an estimated incidence of $\geqslant 200$ per 100,000 ( $r=0.69,95 \%$ CI $0.14-0.91)$ For countries with an estimated incidence of $\geqslant 50$ per 100,000 the association was not significant $(r=0.55,95 \%$ CI $-0.08-0.86)$.

\section{Trends in disease attributed to recent transmission}

On average, an index case had 0.24 (95\% CI $0.21-0.26$ ) secondary cases within 2 yrs. This number was similar for native and foreign-born index cases. Most cases attributable to recent transmission were aged $<45 \mathrm{yrs}$ and were seen in clusters with index cases aged $<45$ yrs (fig. 2).

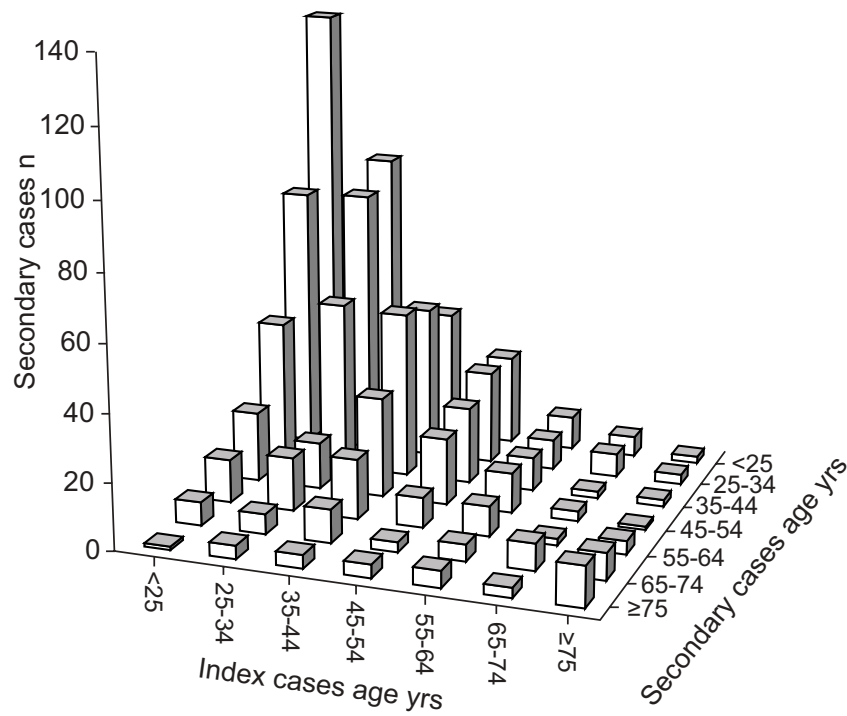

FIGURE 2. The age distribution of 987 secondary cases by age of their 4,198 index cases in the Netherlands, 1995-2005.
Among native index cases, the number of secondary cases did not change over time, was higher for male than female index cases, declined with age and was increased if the index case had smear-positive TB, lived in an urban setting, or abused alcohol (table 4). In univariate analysis, the number of secondary cases was increased if the index case was a drug user, but this was not significant after taking age and alcohol abuse into account.

Among the foreign-born, the number of secondary cases per index case declined by $3 \%(95 \% \mathrm{CI} 0-5 \%, \mathrm{p}=0.045)$ per year. The number of secondary cases declined with age of the index case, was increased if the index case was male, had smear-positive TB, lived in an urban area or was a drug user or homeless (table 5). The number of secondary cases was much lower for index cases born in Asia than for those born outside Asia.

\section{Sensitivity analysis}

The incidence of index cases declined somewhat with an increasing time period to define recent transmission (table 6). The transmission index tended to decline with an increasing time period among native index cases and to increase among the foreign-born. Time trends were not affected by the definition used (table 6).

\section{Summary of results}

From 1995 to 2005 the number of native index cases declined from 170 to 91 and their secondary cases within 2 yrs from 49 (32 native, 17 foreign-born) to 16 (10 native, 6 foreign-born). The number of foreign-born index cases declined from 250 to 222 and their secondary cases within 2 yrs from 53 (13 native, 40 foreign-born) to 37 (10 native, 27 foreign born). Thus, of the total reduction of 202 cases from 1995 to 2005, 42\% was accounted for by fewer native index cases, $23 \%$ by fewer foreign-born index cases, $24 \%$ by fewer secondary cases from native index cases, and $11 \%$ by fewer secondary cases from foreign-born index cases. The proportion of native patients with TB attributable to recent transmission with a foreign-born index case increased from 13 out of $45(29 \%)$ in 1995 to 10 out of $20(50 \%)$ in 2005 (difference 21\%, 95\% CI 5-45\%). 
TABLE 4 Risk factors among native index cases for number of secondary cases within 2 yrs

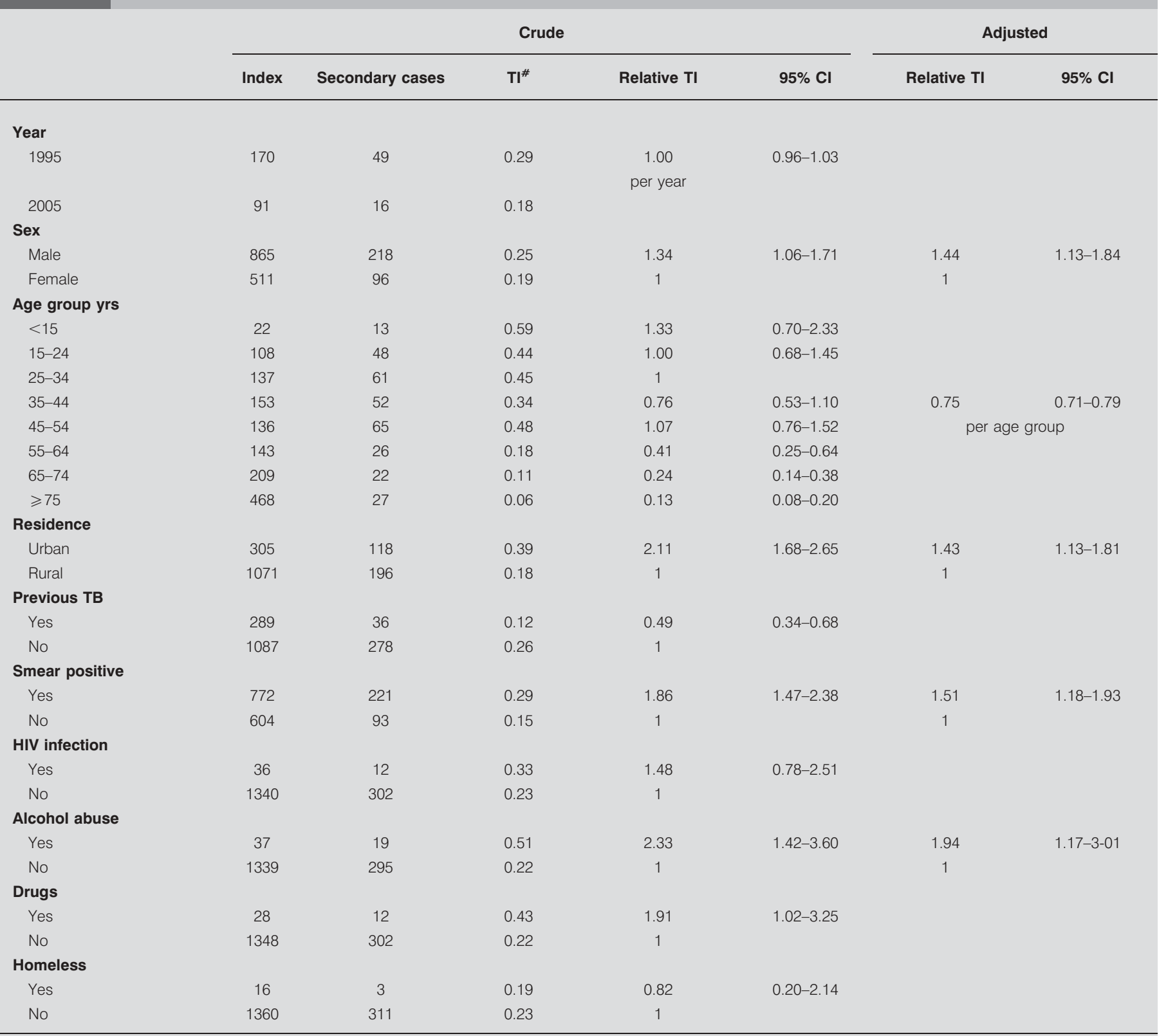

Data are presented as $n$, unless otherwise stated. ${ }^{\#}$ : transmission index (TI) was calculated as number of secondary cases divided by number of index cases.

\section{DISCUSSION}

This study has shown that TB rates in the Netherlands declined in the period 1995-2005 as the result of a reduced incidence of index cases, while maintaining a low number of secondary patients per index case. The decline of index cases was stronger for natives than for the foreign-born. The average number of secondary cases per foreign-born index case declined slightly.

The reduced incidence of native index cases may be attributed mainly to a cohort effect, as suggested previously [9]. This study provides quantitative support for this explanation, since the trend over time of the incidence of native index cases was fairly well predicted by the estimated time trend of the prevalence of LTBI. Discrepancies may have resulted from uncertainties in the age-specific LTBI prevalence estimates, changes in the rate of progression to disease, and from the role of second generation immigrants, who have higher TB rates and, presumably, higher LTBI rates than other natives.

The incidence of index cases among the foreign-born was associated with the number of immigrants from high incidence countries in the same year. This was expected because incidence is highest during the first year after entry [21]. An important intervention to reduce $\mathrm{TB}$ incidence among immigrants is screening for and treatment of latent infection [4]. This strategy is not routinely implemented in the Netherlands, although screening for active TB is in place. 
TABLE 5 Risk factors among foreign-born index cases for number of secondary cases within 2 yrs in the Netherlands, 1995-2005

\begin{tabular}{|c|c|c|c|c|c|c|c|}
\hline & \multicolumn{5}{|c|}{ Crude } & \multicolumn{2}{|c|}{ Adjusted } \\
\hline & Index & Secondary cases & $\mathrm{TI}^{\#}$ & Relative TI & $95 \% \mathrm{Cl}$ & Relative TI & $95 \% \mathrm{Cl}$ \\
\hline \multicolumn{8}{|l|}{ Year } \\
\hline \multirow[t]{2}{*}{1995} & 250 & 53 & 0.21 & 0.97 & $0.95-0.99$ & 0.97 & $0.95-1.00$ \\
\hline & & & & per year & & & \\
\hline Male & 1748 & 475 & 0.27 & 1.47 & $1.25-1.74$ & 1.29 & $1.09-1.53$ \\
\hline Female & 1074 & 198 & 0.18 & 1 & & 1 & \\
\hline \multicolumn{8}{|l|}{ Age group yrs } \\
\hline$<15$ & 72 & 19 & 0.26 & 1.28 & $0.77-2.00$ & & \\
\hline $15-24$ & 680 & 215 & 0.32 & 1.54 & $1.27-1.86$ & & \\
\hline $25-34$ & 957 & 197 & 0.21 & 1 & & & \\
\hline $65-74$ & 132 & 9 & 0.07 & 0.33 & $0.16-0.61$ & & \\
\hline$\geqslant 75$ & 82 & 5 & 0.06 & 0.30 & $0.11-0.65$ & & \\
\hline \multicolumn{8}{|l|}{ Country of birth } \\
\hline Somalia & 308 & 111 & 0.36 & 4.10 & $2.95-5.79$ & 3.72 & $2.66-5.27$ \\
\hline Morocco & 329 & 97 & 0.29 & 3.36 & $2.39-4.77$ & 3.36 & $2.38-4.78$ \\
\hline Turkey & 239 & 78 & 0.33 & 3.72 & $2.61-5.34$ & 3.52 & $2.47-5.07$ \\
\hline Surinam & 116 & 43 & 0.37 & 4.22 & $2.79-6.36$ & 3.90 & $2.55-5.96$ \\
\hline Indonesia & 207 & 14 & 0.07 & 0.77 & $0.41-1.36$ & 0.99 & $0.52-1.75$ \\
\hline Former Soviet Union & 91 & 19 & 0.21 & 2.38 & $1.37-3.97$ & 2.50 & $1.44-4.18$ \\
\hline Other Africa & 572 & 158 & 0.28 & 3.15 & $2.30-4.38$ & 2.72 & $1.99-3.80$ \\
\hline Other Asia & 558 & 49 & 0.09 & 1 & & 1 & \\
\hline Other & 331 & 92 & 0.28 & 3.17 & $2.25-4.51$ & 2.92 & $2.07-4.17$ \\
\hline \multicolumn{8}{|l|}{ Residence } \\
\hline \multicolumn{8}{|l|}{ Smear positive } \\
\hline Yes & 1515 & 462 & 0.30 & 1.89 & $1.61-2.23$ & 1.73 & $1.47-2.05$ \\
\hline No & 1307 & 211 & 0.16 & 1 & & 1 & \\
\hline \multicolumn{8}{|l|}{ HIV infection } \\
\hline Yes & 207 & 46 & 0.22 & 0.93 & $0.68-1.24$ & & \\
\hline No & 2615 & 627 & 0.24 & 1 & & & \\
\hline \multicolumn{8}{|l|}{ Alcohol abuse } \\
\hline Yes & 19 & 3 & 0.16 & 0.66 & $0.16-1.72$ & & \\
\hline No & 2803 & 670 & 0.24 & 1 & & & \\
\hline Drug abuse and homeless & 11 & 22 & 2.00 & 8.91 & $5.65-13.3$ & 7.15 & $4.49-10.8$ \\
\hline Homeless only & 36 & 24 & 0.67 & 2.97 & $1.92-4.36$ & 2.73 & $1.76-4.05$ \\
\hline Drug abuse only & 39 & 13 & 0.33 & 1.49 & $0.81-2.46$ & 1.17 & $0.64-1.96$ \\
\hline Neither & 2736 & 614 & 0.22 & 1 & & 1 & \\
\hline
\end{tabular}

Data are presented as $\mathrm{n}$, unless otherwise stated. ${ }^{*}$ : transmission index (TI) is calculated as number of secondary cases divided by number of index cases.

Risk factors among index cases for a relatively high number of secondary cases, such as young age, male sex and smear positivity, were consistent with earlier findings $[9,14,15,22$, 23]. Transmission among young adults is striking and may reflect the fact that they are socially active and tend to mix with those similar in age [24]. Among immigrants, those born in Indonesia and other Asian countries had a significantly lower transmission index. It will be of interest to determine whether 


\begin{tabular}{|c|c|c|c|c|c|c|c|}
\hline \multirow[t]{3}{*}{ TABLE 6} & \multicolumn{7}{|c|}{$\begin{array}{l}\text { Sensitivity analysis with varying definitions of } \\
\text { recent transmission (1, } 2 \text { or } 3 \text { yrs) in index cases } \\
\text { 1996-2004 }\end{array}$} \\
\hline & & \multicolumn{3}{|c|}{ Native } & \multicolumn{3}{|c|}{ Foreign-born } \\
\hline & & $1 \mathrm{yr}$ & 2 yrs & 3 yrs & $1 \mathrm{yr}$ & 2 yrs & 3 yrs \\
\hline \multicolumn{2}{|l|}{ Index cases } & 1252 & 1115 & 1064 & 2563 & 2350 & 2237 \\
\hline \multicolumn{2}{|c|}{ Secondary cases } & 432 & 304 & 286 & 852 & 855 & 908 \\
\hline \multicolumn{2}{|c|}{$\begin{array}{l}\text { Incidence index cases } \\
\text { per } 100000\end{array}$} & 0.96 & 0.86 & 0.82 & 19.49 & 17.87 & 17.01 \\
\hline \multicolumn{2}{|c|}{ Transmission index } & 0.35 & 0.27 & 0.27 & 0.33 & 0.36 & 0.41 \\
\hline \multicolumn{2}{|c|}{ Time trend index cases } & 0.94 & 0.95 & 0.95 & 0.99 & 0.99 & 0.99 \\
\hline \multicolumn{2}{|c|}{$\begin{array}{l}\text { Time trend transmission } \\
\text { index }\end{array}$} & 1.07 & 1.07 & 1.08 & 0.91 & 0.91 & 0.90 \\
\hline
\end{tabular}

the lower number of secondary cases among Asian index cases is attributable to lower infectiousness of the index patients, lower rates of rapid progression among contacts, host adaptation of the strains circulating in Asia [25], social mixing or a combination of these factors. High rates of transmission among the homeless and drug users have been attributed to low healthcare utilisation and difficulties with contact investigation, necessitating active case-finding in this group [26].

The contribution of foreign-born patients to transmission was not surprising in comparison with other settings. In San Francisco, using more detailed contact investigations, two out of $19(11 \%)$ cases attributed to recent transmission were attributed to a foreign-born source [27]. Using comprehensive DNA fingerprinting results, it was estimated that, in San Francisco, 61 of (89+61) (41\%) of US-born secondary cases were attributable to a foreign-born index case [28]. As in Norway [13], where 23 out of 75 (31\%) native secondary cases were attributed to recent transmission from a foreign-born index case, we observed no overall increase in cases attributable to recent transmission, despite the continuing influx of $\mathrm{TB}$ through immigration.

Clustering percentages and the proportion of patients attributed to recent transmission are underestimated if case-finding is incomplete $[6,29]$. While case notification in the Netherlands is $>85 \%$ complete [30], failure to perfectly match the DNA fingerprint database to the NTR led to loss of $18 \%$ of registered patients. Moreover, in $\sim 5 \%$ of patients with disease due to recent transmission, a transposition may have resulted in a slightly different RFLP pattern [31, 32]. Conversely, transmission may have been overestimated, since not all clustering based on RFLP typing may represent recent transmission. However, in a study in Amsterdam, the Netherlands, with intensive efforts to identify epidemiological links, $86 \%$ of clustered patients were found to have such links [33]. Since the declining trend of all TB patients 1995-2005 was somewhat steeper than that of patients included in the study (fig. 1), our trend estimates may be slightly underestimated. The definition of $\mathrm{TB}$ attributable to rapid progression versus reactivation of latent infection varies from 1 to 5 yrs between authors [1, 2, 7, 34]. We have used a 2-yr period and found that time trends were not sensitive to this definition.
In conclusion, over the past 15 yrs, substantial progress has been made towards TB elimination in the Netherlands. However, given that an increasing proportion of TB cases is foreign-born, elimination of TB is unlikely with current tools and current levels of immigration. In order to accelerate progress towards elimination, the TB programme in the Netherlands needs to explore strategies to expand the diagnosis and treatment of LTBI among the foreign-born. Furthermore, since global control of TB may lead to lower TB rates among immigrants [35], global TB control should be strongly supported by low incidence countries such as the Netherlands.

Major barriers for expanding the diagnosis and treatment of LTBI are the limited validity of diagnostics for predicting disease, side-effects of current regimens, the risk of selecting for drug resistance, and the logistics and costs of ensuring compliance. Therefore, there is a need to invest in research and development of better diagnostics to identify individuals with a high risk to progress to disease, to allow focused preventive treatment, new drugs for preventive treatment and a postexposure vaccine, which would be of great benefit for the elimination of TB in low-incidence countries.

\section{STATEMENT OF INTEREST}

None declared.

\section{ACKNOWLEDGEMENTS}

We thank R.B. Geskus (Academic Medical Centre, University of Amsterdam, Amsterdam, the Netherlands) for critically reviewing an earlier version of this paper.

\section{REFERENCES}

1 Styblo K. Epidemiology of Tuberculosis. Selected papers vol. 24. The Hague, KNCV Tuberculosis Foundation, 1991.

2 Rieder H. Epidemiologic Basis of Tuberculosis Control. Paris, International Union Against Tuberculosis and Lung Disease, 1999.

3 Lillebaek T, Dirksen A, Baess I, et al. Molecular evidence of endogenous reactivation of Mycobacterium tuberculosis after 33 years of latent infection. J Infect Dis 2002; 185: 401-404.

4 Geng E, Kreiswirth B, Driver C, et al. Changes in the transmission of tuberculosis in New York City from 1990 to 1999. N Engl J Med 2002; 346: 1453-1458.

5 Small PM, Hopewell PC, Singh SP, et al. The epidemiology of tuberculosis in San Francisco. A population-based study using conventional and molecular methods. N Engl J Med 1994; 330: 1703-1709.

6 Glynn JR, Vynnycky E, Fine PE. Influence of sampling on estimates of clustering and recent transmission of Mycobacterium tuberculosis derived from DNA fingerprinting techniques. Am J Epidemiol 1999; 149: 366-371.

7 Jasmer RM, Hahn JA, Small PM, et al. A molecular epidemiologic analysis of tuberculosis trends in San Francisco, 1991-1997. Ann Intern Med 1999; 130: 971-978.

8 Iñigo J, Arce A, Palenque E, et al. Decreased tuberculosis incidence and declining clustered case rates, Madrid. Emerg Infect Dis 2008; 14: 1641-1643.

9 Borgdorff MW, van der Werf MJ, de Haas PE, et al. Tuberculosis elimination in the Netherlands. Emerg Infect Dis 2005; 11: 597-602.

10 France AM, Cave MD, Bates JH, et al. What's driving the decline in tuberculosis in Arkansas? A molecular epidemiologic analysis of tuberculosis trends in a rural, low-incidence population, 19972003. Am J Epidemiol 2007; 166: 662-671. 
11 Van Embden JD, Cave MD, Crawford JT, et al. Strain identification of Mycobacterium tuberculosis by DNA fingerprinting: recommendations for a standardized methodology. J Clin Microbiol. 1993; 31: 406-409.

12 Kremer K, van Soolingen D, Frothingham R, et al. Comparison of methods based on different molecular epidemiological markers for typing of Mycobacterium tuberculosis complex strains: interlaboratory study of discriminatory power and reproducibility. J Clin Microbiol 1999; 37: 2607-2618.

13 Dahle UR, Eldholm V, Winje BA, et al. Impact of immigration on the molecular epidemiology of Mycobacterium tuberculosis in a lowincidence country. Am J Respir Crit Care Med 2007; 176: 930-935.

14 Borgdorff MW, Nagelkerke N, van Soolingen D, et al. Analysis of tuberculosis transmission between nationalities in the Netherlands in the period 1993-1995 using DNA fingerprinting. Am J Epidemiol 1998; 147: 187-195.

15 Borgdorff MW, Nagelkerke NJ, De Haas PE, et al. Transmission of tuberculosis depending on the age and sex of source cases. Am Epidemiol 2001; 154: 934-943.

16 Vynnycky E, Borgdorff MW, van Soolingen D, et al. Annual Mycobacterium tuberculosis infection risk and interpretation of clustering statistics. Emerg Infect Dis 2003; 9: 176-183.

17 Central Bureau of Statistics, CBS Statline. statline.cbs.nl/StatWeb/ Date last accessed: May, 20: 2009.

18 World Health Organization. Global Tuberculosis Control: Surveillance, Planning, Financing. Geneva, World Health Organization, 2008.

19 Breslow NE, Day NE. Statistical Methods in Cancer Research. Lyon, International Agency for Research on Cancer, 1987.

20 Styblo K. The elimination of tuberculosis in The Netherlands. Bull Int Union Tuberc Lung Dis 1990; 65: 49-55.

21 Vos AM, Meima A, Verver S, et al. High incidence of pulmonary tuberculosis persists a decade after immigration, The Netherlands. Emerg Infect Dis 2004; 10: 736-739.

22 van Soolingen D, Borgdorff MW, de Haas PE, et al. Molecular epidemiology of tuberculosis in the Netherlands: a nationwide study from 1993 through 1997. J Infect Dis 1999; 180: 726-736.
23 Behr MA, Warren SA, Salamon $\mathrm{H}$, et al. Transmission of Mycobacterium tuberculosis from patients smear-negative for acidfast bacilli. Lancet 1999; 353: 444-449.

24 Robins AB. The age relationship of cases of pulmonary tuberculosis and their associates. Am J Public Health 1953; 43: 718-723.

25 Gagneux S, DeRiemer K, Van T, et al. Variable host-pathogen compatibility in Mycobacterium tuberculosis. Proc Natl Acad Sci USA 2006; 103: 2869-2873.

26 de Vries G, van Hest RA, Richardus JH. Impact of mobile radiographic screening on tuberculosis among drug users and homeless persons. Am J Respir Crit Care Med 2007; 176: 201-207.

27 Chin DP, DeRiemer K, Small PM, et al. Differences in contributing factors to tuberculosis incidence in US-born and foreign-born persons. Am J Respir Crit Care Med 1998; 158: 1797-1803.

28 Borgdorff MW, Behr MA, Nagelkerke NJ, et al. Transmission of tuberculosis in San Francisco and its association with immigration and ethnicity. Int J Tuberc Lung Dis 2000; 4: 287-294.

29 Murray M. Sampling bias in the molecular epidemiology of tuberculosis. Emerg Infect Dis 2002; 8: 363-369.

30 van Hest NA, Smit F, Baars HW, et al. Completeness of notification of tuberculosis in The Netherlands: how reliable is record-linkage and capture-recapture analysis? Epidemiol Infect 2007; 135: 1021-1029.

31 de Boer AS, Borgdorff MW, de Haas PE, et al. Analysis of rate of change of IS6110 RFLP patterns of Mycobacterium tuberculosis based on serial patient isolates. J Infect Dis 1999; 180: 1238-1244.

32 Eilers PHC, van Soolingen D, Lan NTN, et al. Transposition rates of Mycobacterium tuberculosis IS6110 restriction fragment length polymorphism patterns. J Clin Microbiol 2004; 42: 2461-2464.

33 van Deutekom H, Hoijng SP, de Haas PE, et al. Clustered tuberculosis cases: do they represent recent transmission and can they be detected earlier? Am J Respir Crit Care Med 2004; 169: 806-810.

34 Sanchez MA, Blower SM. Uncertainty and sensitivity analysis of the basic reproductive rate. Tuberculosis as an example. Am J Epidemiol 1997; 145: 1127-1137.

35 Schwartzman K, Oxlade O, Barr RG, et al. Domestic returns from investment in the control of tuberculosis in other countries. $N$ Engl J Med 2005; 353: 1008-1020. 